\title{
Gwiazda on the Bayesian argument for God
}

\author{
Richard Swinburne
}

[Swinburne, Richard, 2011, "Gwiazda on the Bayesian argument for God", Philosophia, 39 no.2, 393-396.]

\begin{abstract}
Jeremy Gwiazda made two criticisms of my formulation in terms of Bayes's theorem of my probabilistic argument for the existence of God. The first criticism depends on his assumption that I claim that the intrinsic probabilities of all propositions depend almost entirely on their simplicity; however, my claim is that that holds only insofar as those propositions are explanatory hypotheses. The second criticism depends on a claim that the intrinsic probabilities of exclusive and exhaustive hypotheses of a phenomenon must sum to 1; however it is only those probabilities plus the intrinsic probability of the non-occurrence of the phenomenon which must sum to 1 .
\end{abstract}

Keywords: Gwiazda, the existence of God, Bayes's theorem, Swinburne.

Jeremy Gwiazda (2010) gives two main criticisms of my Bayesian argument for the existence of God. I use Bayes's theorem, $\mathrm{P}(\mathrm{h} \mid \mathrm{e} \& \mathrm{k})=\mathrm{P}(\mathrm{e} \mid \mathrm{h} \& \mathrm{k}) \mathrm{P}(\mathrm{h} \mid \mathrm{k}) / \mathrm{P}(\mathrm{e} \mid \mathrm{k})$

to assess the probability of the existence of God (h) on the evidence (that is,data) of the most general features of the world (e). $\mathrm{k}$ is 'mere tautological evidence', and so $\mathrm{P}(\mathrm{h} \mid \mathrm{k})$ is the intrinsic probability of $\mathrm{h}$ (its a priori probability), and $\mathrm{P}(\mathrm{e} \mid \mathrm{k})$ is the intrinsic probability of $\mathrm{e}$. Although we cannot often give exact values to the probabilities of hypotheses or other propositions, we can often give rough values or comparative values to them. I claimed that the intrinsic probability of a hypothesis depends solely on its simplicity and its scope (that is content, the range and detail of its claims).Since I claimed that the intrinsic probability of a hypothesis depends far more on its simplicity than on its scope, and since Gwiazda does not bring scope into his discussion, I shall henceforward ignore the role of scope. So since - I claim- $h$ is a very simple hypothesis and rival hypotheses which purport to explain the same evidence are very complex- $h$ has a far higher intrinsic probability than they do. But I also suggested that since a priori it is most improbable that anything at all should exist, in absolute terms $\mathrm{P}(\mathrm{h} \mid \mathrm{k})$ is very low. I gave reason to suppose that (very roughly) $\mathrm{P}(\mathrm{e} \mid \mathrm{h} \& \mathrm{k})=1 / 2$. Gwiazda points out that in consequence, in order to conform to the axioms of the calculus, I must maintain that $\mathrm{P}(\mathrm{h} \mid \mathrm{k}) / \mathrm{P}(\mathrm{e} \mid \mathrm{k})<2$. He claims that, given the complexity of e (relative to $h$ ), this ratio ought to be far greater than 2. However, Gwiazda has misunderstood me, because he supposes that we can assess the simplicity of every proposition in isolation 
from any consideration of what - if that proposition were true - could explain that proposition being true.

My discussions of simplicity were mostly concerned with examples of high-level or medium-level hypotheses (that is, theories) postulated to explain some collection of evidence, where we can ignore the relevance of yet higher-level hypotheses which might explain the former. In these cases the simplicity of a hypothesis is a matter of it postulating few entities, few kinds of entity, few properties, few kinds of property, more readily observable properties and ones connected by few laws of a mathematically simple kind (mathematical simplicity being precisely defined) (Swinburne 2001, 83-99). And of course with $\mathrm{h}$ as theism there could be no higher-level hypothesis which explains it; and so these considerations are alone relevant to determining its simplicity. But where there is a possibility of higher-level hypotheses, the extent to which medium-level hypotheses might fit with other medium-level hypotheses into a higher-level hypothesis is relevant to determining their simplicity. I wrote (Swinburne 2001, 96):

We should postulate, on grounds of simplicity as most likely to be true, that theory of a narrow region which makes our overall world theory the simplest for the total data. That theory may not be the simplest theory of the narrow aspect of the world, considered on its own.

So the intrinsic probability of propositions which explain less will be a function of how simple are the propositions which, if true, would explain them (and the probability that the latter propositions give to the former); though it would normally be right to assume that the medium-level hypothesis which is the simplest when considered on its own, will fit into the simplest highest-level hypothesis better than will other medium-level hypotheses which are more complicated when considered on their own. And so the intrinsic probability of propositions which explain nothing will be a function of how well, if true, they could be explained by simple propositions. So the intrinsic probability of a world is a function of how simple are the highestlevel hypotheses which it contains and how well they are able to explain all the other propositions which the world contains. That leads to this general result for the intrinsic probability of all propositions (Swinburne 2001,118):

The intrinsic probability of any proposition is the sum of the intrinsic probabilities of all the worlds to which it belongs.

It follows (Swinburne 2004, 339) from the axioms of the calculus that:

$$
\mathrm{P}(\mathrm{e} \mid \mathrm{k})=\mathrm{P}(\mathrm{e} \& \mathrm{~h} \mid \mathrm{k})+\mathrm{P}(\mathrm{e} \& \sim \mathrm{h} \mid \mathrm{k})
$$

and so 


$$
\mathrm{P}(\mathrm{e} \mid \mathrm{k})=\mathrm{P}(\mathrm{e} \mid \mathrm{h} \& \mathrm{k}) \mathrm{P}(\mathrm{h} \mid \mathrm{k})+\mathrm{P}(\mathrm{e} \mid \sim \mathrm{h} \& \mathrm{k}) \mathrm{P}(\sim \mathrm{h} \mid \mathrm{k})
$$

Hence (Swinburne 2004, 340; cited by Gwiazda 2010, 362):

$\mathrm{P}(\mathrm{e} \mid \sim \mathrm{h} \& \mathrm{k}) \mathrm{P}(\sim \mathrm{h} \mid \mathrm{k})=\mathrm{P}\left(\mathrm{e} \mid \mathrm{h}_{1} \& \mathrm{k}\right) \mathrm{P}\left(\mathrm{h}_{1} \mid \mathrm{k}\right)+\mathrm{P}\left(\mathrm{e} \mid \mathrm{h}_{2} \& \mathrm{k}\right) \mathrm{P}\left(\mathrm{h}_{2} \mid \mathrm{k}\right)+\mathrm{P}\left(\mathrm{e} \mid \mathrm{h}_{3}\right.$ $\& \mathrm{k}) \mathrm{P}\left(\mathrm{h}_{3} \mid \mathrm{k}\right)$

where $h, h_{1} h_{2}$ and $h_{3}$ are exclusive and exhaustive hypotheses which -if true- could explain e. So the intrinsic probability of e is a function of the intrinsic probability of the different hypotheses which could explain it and the probability of e on those hypotheses. So, given my claim that $h_{1}, h_{2}$ and $h_{3}$ are far more complicated than $h, P(e \mid k)$ will not be much greater than $\mathrm{P}(\mathrm{e} \mid \mathrm{h} \& \mathrm{k}) \mathrm{P}(\mathrm{h} \mid \mathrm{k})$, and so $\mathrm{P}(\mathrm{h} \mid \mathrm{k}) / \mathrm{P}(\mathrm{e} \mid \mathrm{k})$ will be less than 2 .

Gwiazda's other criticism arises from his claim that where $h_{1}, h_{2}$, and $h_{3}$ are the only possible explanations of e, other than $h$ :

$$
\mathrm{P}(\mathrm{h} \mid \mathrm{k})+\mathrm{P}\left(\mathrm{h}_{1} \mid \mathrm{k}\right)+\mathrm{P}\left(\mathrm{h}_{2} \mid \mathrm{k}\right)+\mathrm{P}\left(\mathrm{h}_{3} \mid \mathrm{k}\right)=1
$$

which, he rightly points out, would lead to enormous difficulties for me. However his claim is manifestly false. It is only the case that one of these hypotheses must be true, if e is true. But a priori e may not be true. There is the possibility that there be a different kind of world from our world, not caused by God or gods (let's call that ' $d$ '), and the possibility that nothing exist (let's call that ' $n$ '). I suggested that the intrinsic probabilities of $h, h_{1}, h_{2}$, and $h_{3}$ are all be very small, and the intrinsic probability of $n$ is very high. Given these values, it doesn't affect the argument what is the intrinsic probability of $\mathrm{d}$. It is only probabilities which are exclusive and exhaustive of the field which - it follows from the probability axioms - must sum to 1 . So where the field consists of all the possibilities which could obtain, given $\mathrm{k}$, the relevant equation is:

$\mathrm{P}(\mathrm{h} \mid \mathrm{k})+\mathrm{P}\left(\mathrm{h}_{1} \mid \mathrm{k}\right)+\mathrm{P}\left(\mathrm{h}_{2} \mid \mathrm{k}\right)+\mathrm{P}\left(\mathrm{h}_{3} \mid \mathrm{k}\right)+\mathrm{P}(\mathrm{d} \mid \mathrm{k})+\mathrm{P}(\mathrm{n} \mid \mathrm{k})=1$

though also:

$\mathrm{P}(\mathrm{h} \mid \mathrm{e} \& \mathrm{k})+\mathrm{P}\left(\mathrm{h}_{1} \mid \mathrm{e} \& \mathrm{k}\right)+\mathrm{P}\left(\mathrm{h}_{2} \mid \mathrm{e} \& \mathrm{k}\right)+\mathrm{P}\left(\mathrm{h}_{3} \mid \mathrm{e} \& \mathrm{k}\right)=1$

So I suggest neither of Gwiazda's criticisms of my Bayesian argument have any cogency ${ }^{1}$. Gwiazda asks for a possible assignment of probabilities which would yield my conclusion that $\mathrm{P}(\mathrm{h} \mid \mathrm{e} \& \mathrm{k})$ be greater than $1 / 2$. I have already claimed that (roughly) $\mathrm{P}(\mathrm{e} \mid \mathrm{h} \& \mathrm{k})=1 / 2$. Here are some possible values for the other relevant terms: $\mathrm{P}(\mathrm{h} \mid \mathrm{k})=0.01$. $\mathrm{P}(\mathrm{h} 1 \mid \mathrm{k})=0.0005, \mathrm{P}(\mathrm{h} 2 \mid \mathrm{k})=0.00001, \mathrm{P}(\mathrm{h} 3 \mid \mathrm{k})=(\mathrm{a}$ very small number $), \quad P(d \mid k)=0.005, \quad P(e \mid h 1 \& k)=P(e \mid h 2 \& k)=P(e \mid$ $\mathrm{h} 3 \& \mathrm{k})=1$. 


\section{References}

1. Gwiazda, J. (2010) Richard Swinburne, The Existence of God, and exact numerical values Philosophia, 38, 357-363.

2. Swinburne, R. (2001). Epistemic Justification. Oxford: Clarendon.

3. Swinburne, R. (2004). The Existence of God, $2^{\text {nd }}$ edition. Oxford: Clarendon.

\section{NOTES}

1. In fairness I must confess that it needs some detailed examination of both of two books of mine to see why I am immune to the first criticism; and, while my answer to the second criticism is manifest, I am largely responsible for Gwiazda's failure to see this in virtue of a very misleading answer which I gave to a query of his is in a private e-mail. 